\title{
SEGREGATION OF THE ENVIRONMENTALLY INDUCED RELATIVE MOBILITY SHIFTS IN FLAX GENOTROPH PEROXIDASE ISOZYMES
}

\author{
H. TYSON, S. A. TAYLOR and M. A. FIELDES \\ Biology Department, McGill University, Montreal, Quebec, Canada
}

Received 27.vi.77

\begin{abstract}
Summary
Crosses were made in all combinations between the large ( $L$ ) and small (S) flax genotrophs, and their reciprocal $F_{1}$ 's. Total main stem peroxidase activity was measured prior to electrophoretic separation; individual anionic isozyme relative mobilities ( $\boldsymbol{R}_{m}$ 's) were obtained from electrophoresis of main stem homogenates. Both activity and $R_{m}$ were examined in parent, $\mathrm{F}_{1}, \mathrm{~F}_{2}$ and backcross generations on an individual plant basis. Segregation for isozyme $R_{m}$ occurred, and indicated control over each isozyme's $R_{m}$ by a simple system with a dominant allele in $\mathrm{L}$ and a recessive in $S$. For activity, dominance was absent, and there was no evidence of segregation.
\end{abstract}

\section{INTRODUCTION}

THE presence of $R_{m}$ differences between corresponding anionic peroxidase isozymes from the $\mathrm{L}$ and $\mathrm{S}$ genotrophs of Durrant (1971) has been described by Fieldes and Tyson $(1972,1973 a, b)$. All these anionic isozymes displayed IAA oxidase activity (Fieldes, Deal and Tyson, 1977); such activity indicated their possible involvement in the control of growth and morphology through regulation of IAA level within stem tissues. The initial studies, using acrylamide gel electrophoresis of pooled extracts from individual $\mathrm{L}$ or $\mathrm{S}$ plants, showed that each of the anionic peroxidase isozymes displayed a shift, with the $\mathrm{L}$ isozymes all moving slightly faster than their $\mathrm{S}$ counterparts. The activities of $\mathrm{S}$ isozymes were higher than those of the corresponding $\mathrm{L}$ isozymes, and subsequent purification of the $\mathrm{L}$ and $\mathrm{S}$ isozymes has shown that this reflected increased enzyme production in $\mathrm{S}$ compared to $\mathrm{L}$, on a per unit fresh weight basis (Fieldes, Deal and Tyson, 1977). An additional feature of these environmentally induced heritable shifts in isozyme $R_{m}$ was that subsequent treatments of the same type as those used in the $\mathrm{C}_{0}$, or original treatment generation, resulted in further shifts in $R_{m}$ being superimposed on those shifts already present through induction in the $\mathrm{C}_{0}$ (Fieldes and Tyson, 1972). Studies of pooled homogenates from L, S and the $\mathrm{L}$ by $\mathrm{S}$ reciprocal $\mathrm{F}_{1}$ 's showed that the $R_{m}$ shift was dominant in the hybrid towards L (Fieldes and Tyson, 1973b).

The studies mentioned above dealt with information from generation means. The next step, measurement of $R_{m}$ in individual plants of segregating generations from the $\mathrm{L}$ by $\mathrm{S}$ cross, is described in detail here. The first two isozymes, i.e. the slowest two, were examined; total peroxidase activity of all isozymes in extracts prior to electrophoresis was also measured on an individual plant basis. Evidence was obtained for the first time of simple Mendelian control of the environmentally induced $R_{m}$ difference between the $\mathrm{L}$ and $\mathrm{S}$ genotrophs, a control mediated through a dominant and recessive allele. 


\section{MATERIALS AND METHODS}

Under growth chamber conditions, $\mathrm{L}, \mathrm{S}$ and their reciprocal $\mathrm{F}_{1}$ 's were crossed; the crossing scheme is shown below:

\begin{tabular}{lcccc} 
Female & \multicolumn{4}{c}{ Male parents } \\
parents: & $\overbrace{\mathrm{L} \times \mathrm{L}(1)}$ & $\mathrm{L} \times \mathrm{S}(2)$ & $\mathrm{S} \times \mathrm{L}(3)$ & $\mathrm{S} \times \mathrm{S}(4)$ \\
$\mathrm{L} \times \mathrm{L}(1)$ & 11 & 12 & 13 & 14 \\
$\mathrm{~L} \times \mathrm{S}(2)$ & 21 & 22 & 23 & 24 \\
$\mathrm{~S} \times \mathrm{L}(3)$ & 31 & 32 & 33 & 34 \\
$\mathrm{~S} \times \mathrm{S}(4)$ & 41 & 42 & 43 & 44
\end{tabular}

Types of offspring are identified by the two digit code indicating parentage.

Plants of all 16 types of offspring were grown in vermiculite, using a modified form of the nutrient solution of Murashige and Skoog (1962), under growth chamber conditions. Resultant approximate amounts of $\mathcal{N}, P$ and $K$ supplied, on a per plant basis, were respectively $0.13 \mathrm{~g}, 0.02 \mathrm{~g}$ and $0.15 \mathrm{~g}$. Temperature was cycled from $14^{\circ} \mathrm{C}$ to $22^{\circ} \mathrm{C}$ on a 24-hour basis; daylength was 20 hour. Each replicate contained one plant of each of the 16 offspring types; 14 complete replicates were available for main stem extract preparation, as detailed by Fieldes and Tyson (1972), 35 days after germination. The 16 extracts from a replicate were run on a single acrylamide gel slab, using the electrophoresis techniques, and subsequent staining and scanning methods described by Hart, Tyson and Bloomberg (1971). Two complete runs were made with the extracts from a replicate; duplicate $R_{m}$ values for isozyme 1 or 2 from a given offspring type in a replicate were averaged for further analysis. Total peroxidase activity was measured on each extract.

The average $R_{m}$ 's for isozymes 1 and 2 for each of the 14 replicates reflected differences in growth conditions, in electrophoresis procedures, and conceivably in the numbers of $L$ or $S$ segregants in the $F_{2}, B_{1}$ and $B_{2}$ generations for each replicate. Differences in replicate mean $R_{m}$ 's meant that simple classification into $\mathrm{L}$ or $\mathrm{S}$ type segregants could have been confused by overlapping of $\mathrm{L}$ or $\mathrm{S}$ type segregants from various replicates. To obtain a correction for the replicate differences, the regressions of mean $R_{m}$ for all $\mathrm{F}_{1}, \mathrm{~F}_{2}, \mathrm{~B}_{1}$ and $\mathrm{B}_{2}$ progenies in a replicate on either the $\mathrm{L}$ or the $\mathrm{S}$ parental $R_{m}$ in that replicate were calculated across all 14 replicates. Isozyme 1 data were examined separately from isozyme 2 data.

There were thus four regressions; each was significant. Neither the $\mathrm{L}$ or $\mathrm{S}$ regressions for isozyme 1, nor those for isozyme 2, differed significantly in slope. In both cases, therefore, the joint regressions through $\mathrm{L}$ and $\mathrm{S}$, using within $\mathrm{L}$ and within $\mathrm{S}$ sums of squares and cross products, summarised the changes in progenies' mean $R_{m}$ with parent mean $R_{m}$, i.e. $\frac{1}{2}(\mathrm{~L}+\mathrm{S})$, across replicates. The positions of the joint regression for either isozyme 1 data, or for isozyme 2 , were set at $\frac{1}{2}(\mathrm{~L}+\mathrm{S})$ on the $y$ axis. In other words, $b_{0}$ in the equation: $Y=b_{0}+b_{1}(x-\bar{x})$, had the overall mean value for L (11) and $\mathrm{S}(44) R_{m}$ 's. The positions of these lines for isozyme 1 or for isozyme 2 suggested that they could be used (a) to make a distinction between $\mathrm{L}$ and $\mathrm{S}$ types in the 224 isozyme 1 or 2 values of all five generations examined, and (b), to adjust individual $R_{m}$ values in all five generations to the same midparent $R_{m}$ value for isozyme 1 or for isozyme 2 data. 
Both (a) and (b) were carried out for each isozyme's data. For (a), individuals in all generations were classified as $\mathrm{L}$ or $\mathrm{S}$, or as indeterminate, by setting up 95 per cent confidence limits above and below the joint regression line. Those points above the upper limit were classified as $L$ segregants; those below the lower limit were classified as S. Points falling between the two limits, i.e. close to the joint regression line, were regarded as indeterminate. This resulted in the tabulation of numbers of $\mathrm{L}$ and $\mathrm{S}$ types in all five generations for each isozyme. The classification achieved with (a) for isozyme 1 data was compared with that for isozyme 2 data. Individuals classified as, say, $L$ segregants with isozyme 1 data, were checked to see if this was also true for isozyme 2. For (b), adjustment to a common midparent value across all replicates was coupled with the histogramming of isozyme 1 or 2 adjusted data, as well as adjusted total peroxidase data.

Finally, analyses of variance of peroxidase activity, isozyme 1 and isozyme 2 data were separately carried out. The orthogonal comparisons made amongst the 16 types of offspring are shown in table 1 .

TABLE 1

Orthogonal breakdown of the 15 degrees of freedom for offspring types

Comparison

$\begin{array}{rrrrrrrrrrrrrrrrr} & 11 & 12 & 13 & 14 & 21 & 22 & 23 & 24 & 31 & 32 & 33 & 34 & 41 & 42 & 43 & 44 \\ 1 & 1 & - & - & - & - & - & - & - & - & - & - & - & - & - & - & -1 \\ 2 & - & - & - & 1 & - & - & - & - & - & - & - & - & -1 & - & - & - \\ 3 & 1 & - & - & -1 & - & - & - & - & - & - & - & - & -1 & - & - & 1 \\ 4 & - & - & - & - & - & 1 & 1 & - & - & -1 & -1 & - & - & - & - & - \\ 5 & - & - & - & - & - & 1 & -1 & - & - & 1 & -1 & - & - & - & - & - \\ 6 & - & - & - & - & - & 1 & -1 & - & - & -1 & 1 & - & - & - & - & - \\ 7 & - & 1 & 1 & - & -1 & - & - & - & -1 & - & - & - & - & - & - & - \\ 8 & - & 1 & -1 & - & 1 & - & - & - & -1 & - & - & - & - & - & - & - \\ 9 & - & 1 & -1 & - & -1 & - & - & - & 1 & - & - & - & - & - & - & - \\ 10 & - & - & - & - & - & - & - & 1 & - & - & - & 1 & - & -1 & -1 & - \\ 11 & - & - & - & - & - & - & - & 1 & - & - & - & -1 & - & 1 & -1 & - \\ 12 & - & - & - & - & - & - & - & 1 & - & - & - & -1 & - & -1 & 1 & - \\ 13 & - & 1 & 1 & - & 1 & - & - & -1 & 1 & - & - & -1 & - & -1 & -1 & - \\ 14 & 1 & - & - & 1 & -1 & -1 & -1 & - & - & -1 & -1 & - & 1 & - & - & 1 \\ 15 & 1 & -1 & -1 & 1 & -1 & 1 & 1 & -1 & -1 & 1 & 1 & -1 & 1 & -1 & -1 & 1\end{array}$

\section{REsULts}

The 16 offspring type means for peroxidase activity, isozyme 1 and $2 R_{m}$ are shown in table 2 . Analyses of variance on each character are summarised in table 3 . In the offspring type breakdown of peroxidase activity only the parental $(\mathrm{L}-\mathrm{S})$ and backcross $\left(\bar{B}_{1}-\bar{B}_{2}\right)$ differences were significant indicating the absence of dominance. Observed and expected generation means corresponded well on this basis. On the other hand, both isozyme 1 and $2 R_{m}$ 's displayed dominance since the same breakdown also revealed a significant difference between the midparent $R_{m}$ and that of the $F_{1}$ reciprocal mean. On the basis of the parental and $F_{1}$ values, the expected $\mathrm{F}_{2}$ agreed closely with that observed; other expected generation means for both isozymes showed similar close agreement with those observed. 
There was a significant interaction for isozyme 2, which suggested a type of cytoplasmic effect on $R_{m}$ in a backcross.

When the results from the classification with procedure (a), shown in table 4 were examined, there appeared to be fewer indeterminate points for isozyme 2 data compared to isozyme 1 . This stemmed essentially from the shorter migration distance of isozyme 1 , and the consequent difficulty of resolving the smaller $\mathrm{L}$ to $\mathrm{S}$ difference as accurately as with isozyme 2 . Although the number of indeterminates was higher for isozyme 1 data, apart from the $\mathrm{F}_{2}\left(\chi^{2}=1 \cdot 1046, \mathrm{P}\right.$ between $0 \cdot 2$ and $\left.0 \cdot 3\right)$, all other ratios

TABLE 2

Offspring type means over 14 replicates

\begin{tabular}{|c|c|c|c|}
\hline Type & $\begin{array}{l}\text { Peroxidase } \\
\text { activity* }\end{array}$ & Iso. I $R_{m}$ & Iso. $2 R_{m}$ \\
\hline 11 & $17 \cdot 07$ & 0.0743 & $0 \cdot 1708$ \\
\hline 12 & $17 \cdot 08$ & $0 \cdot 0743$ & $0 \cdot 1712$ \\
\hline 13 & $18 \cdot 88$ & $0 \cdot 0740$ & $0 \cdot 1697$ \\
\hline 14 & $18 \cdot 93$ & $0 \cdot 0746$ & $0 \cdot 1716$ \\
\hline 21 & $\mathrm{I} 8 \cdot 82$ & $0 \cdot 0742$ & $0 \cdot 1696$ \\
\hline 22 & $20 \cdot 64$ & 0.0712 & 0.1613 \\
\hline 23 & $19 \cdot 30$ & 0.0732 & $0 \cdot 1674$ \\
\hline 24 & $20 \cdot 21$ & 0.0718 & $0 \cdot 1652$ \\
\hline 31 & $19 \cdot 01$ & $0 \cdot 0744$ & $0 \cdot 1700$ \\
\hline 32 & $18 \cdot 42$ & 0.0722 & $0 \cdot 1657$ \\
\hline 33 & $19 \cdot 3 I$ & 0.0729 & $0 \cdot 1653$ \\
\hline 34 & $20 \cdot 47$ & 0.0695 & $0 \cdot 1578$ \\
\hline 41 & $20 \cdot 28$ & 0.0735 & $0 \cdot 1681$ \\
\hline 42 & $20 \cdot 25$ & 0.0708 & $0 \cdot 1584$ \\
\hline 43 & $20 \cdot 9 \mathrm{I}$ & 0.0710 & $0 \cdot 1608$ \\
\hline 44 & $21 \cdot 99$ & $0 \cdot 0670$ & $0 \cdot 1506$ \\
\hline
\end{tabular}

* Activity expressed as $\Delta$ O.D. $\mathrm{min}^{-1} \mathrm{ml}^{-1}$.

Generation means for each character

$\begin{array}{llll}\overline{\mathrm{L}} & 17 \cdot 07 & 0 \cdot 0743 & 0 \cdot 1708 \\ \overline{\mathrm{B}}_{1} & 18 \cdot 45 & 0 \cdot 0742 & 0 \cdot 1701 \\ \overline{\mathrm{F}}_{\mathrm{I}} & 19 \cdot 60 & 0 \cdot 0741 & 0 \cdot 1699 \\ \mathrm{~B}_{2} & 20 \cdot 46 & 0 \cdot 0708 & 0 \cdot 1606 \\ \overline{\mathrm{F}}_{2} & 19 \cdot 42 & 0 \cdot 0724 & 0 \cdot 1649 \\ \mathrm{~S} & 21 \cdot 99 & 0 \cdot 0670 & 0 \cdot 1506 \\ \frac{1}{2}(\overline{\mathrm{L}}+\mathrm{S}) & 19.53 & 0 \cdot 0707 & 0 \cdot 1607\end{array}$

in isozyme I data agreed almost perfectly with those based on a simple Mendelian model with two alleles at one locus, where $\mathrm{L}$ was homozygous dominant, and $\mathrm{S}$ homozygous recessive. The isozyme 2 data were totally in agreement with this model.

A critical point concerned the correlation between the classification of each individual on isozyme 1's data versus its classification with isozyme 2 data. The lower part of table 4 shows the comparison between the two classifications; it is clear that the number of reversals over the total of 224 individuals classified was extremely small (6/224). Amongst the 168 individuals in generations where segregation could occur, five of these six reversals occurred. Such reversals would be either genuine recombination, 
or mis-classification through inherent inaccuracies in the classification procedure. The particular techniques used would not distinguish between these possibilities. Only one individual was indeterminate in both its isozyme 1 and 2 data.

The evidence from the (a) procedure and the correlation just described would overwhelmingly support the contention that there is either a single

TABLE 3

Analysis of variance of peroxidase activity

$\quad$ Source
Total
Between replicates
Between offspring types
Error
Offspring type breakdown:
$\begin{array}{ll}\text { 1. }(\mathrm{L}-\mathrm{S}) & \mathrm{F}=27 \cdot 87 * * \\ \text { 13. }\left(\mathrm{B}_{1}-\mathrm{B}_{2}\right) & \mathrm{F}=18 \cdot 70^{* *}\end{array}$

Analysis of variance of isozyme $1 \mathbf{R}_{m}$

Total

Between replicates

d.f.

Mean squares

F

223

80.72

$15 \quad 24.73$

$195 \quad 6.07$

$4 \cdot 07 * *$

Between offspring types

$0 \cdot 1058 \times 10^{-3}$

$0.0632 \times 10^{-3}$

$10 \cdot 42 * *$

Error

Offspring type breakdown:

1. $(\mathrm{L}-\mathrm{S}) \quad \mathrm{F}=36 \cdot 39 * *$

3. $(\overline{\mathrm{L}+\mathrm{S}})-\mathrm{F}_{1} \quad \mathrm{~F}=16 \cdot 08 * *$

13. $\left(\bar{B}_{1}-\bar{B}_{2}\right) \quad F=32 \cdot 87 * *$

a One missing value fitted.

Analysis of variance of isozyme 2 data

Total

223

Between replicates

$0.0739 \times 10^{-2}$

$0.0498 \times 10^{-2}$

Between offspring types

15

$193^{\circ}$

$0.0062 \times 10^{-2}$

$12 \cdot 02 * *$

$8 \cdot 10 * *$

Offspring type breakdown:

1. $(\mathrm{L}-\mathrm{S}) \quad \mathrm{F}=46.47 * *$

3. $(\overline{\mathrm{L}+\mathrm{S}})-\overline{\mathrm{F}}_{1} \quad \mathrm{~F}=19 \cdot 24 * *$

12. $F=5.67$ *

13. $\left(\bar{B}_{1}-\bar{B}_{2}\right) \quad F=41 \cdot 56 * *$

$b$ Two missing values fitted.

** Significant at probability 0.01 .

* Significant at probability 0.05.

locus, with a dominant and a recessive allele, controlling the $R_{m}$ shift, or else two loci, each with two such allles, closely linked in coupling.

The histograms of the adjusted $R_{m}$ values for isozymes 1 and 2 (figs. 1 and 2) corroborate the classification shown in table 4 from the use of joint regression lines. Isozyme 1 data do not show the distinct segregation found for isozyme 2, but the general trends shown in fig. 1 correspond well with those in fig. 2. A discriminant function calculated from the adjusted 
parental $\mathrm{L}$ and $\mathrm{S} R_{m}$ 's for 1 and 2 did not improve discrimination over that possible with isozyme 2's data alone.

The adjusted values of activity have been histogrammed in fig. 3 , and showed no evidence of segregation.

TABLE 4

Classification of all individuals in five generations into $L, S$ or indeterminate through regressions of figs. 1 and 2

\begin{tabular}{|c|c|c|c|c|c|c|}
\hline & & Iso & ne 1 & & & ne 2 \\
\hline & $\mathbf{L}$ & $\mathrm{S}$ & Indeterminate & $\mathrm{L}$ & $\mathrm{S}$ & Indeterminate \\
\hline $\mathrm{L}$ & 14 & 0 & 0 & 14 & 0 & 0 \\
\hline $\mathrm{F}_{1}$ & 23 & 0 & 5 & 26 & 2 & 0 \\
\hline $\mathrm{B}_{\mathrm{i}}$ & 47 & 2 & 7 & 54 & 1 & 1 \\
\hline $\mathrm{B}_{2}$ & 25 & 25 & 6 & 27 & 28 & 1 \\
\hline$F_{2}$ & 35 & 16 & 5 & 40 & 15 & 1 \\
\hline $\mathrm{S}^{2}$ & 1 & 12 & 1 & 0 & 13 & 1 \\
\hline
\end{tabular}

Comparison of classificanons made Jor isozyme 1 with that for isozyme 2

1. Classified as $L$ in both isozymes 1 and 2

2. Classified as $\mathrm{S}$ in both isozymes 1 and $2=51$

3. Indeterminate in both isozymes 1 and $2=1$

4. Indeterminate for isozyme 2 , classified for isozyme $1=3$ (2 L's, $1 \mathrm{~S}$ )

5. Indeterminate for isozyme 1, classified for isozyme $2=23$ (19 L's, 4 S's)

6. Classified as L for isozyme $1, \mathrm{~S}$ for isozyme $2=3$

7. Classified as $\mathrm{S}$ for isozyme 1, $\mathrm{L}$ for isozyme $2=3$

Total $=224$

\section{Discussion}

Our findings showed that $R_{m}$ 's of two anionic stem peroxidase isozymes in $\mathrm{L}$ and $\mathrm{S}$ were controlled by dominant and recessive alleles. $\mathrm{L}$ was homozygous dominant. Either one single locus was involved in controlling both isozymes' $R_{m}$ 's, or else there were two loci closely linked in coupling. Extension of the $R_{m}$ measurements to the remaining isozymes separated will help to resolve the number of loci involved.

In relation to the molecular differences which exist between corresponding peroxidase isozymes of $\mathrm{L}$ and $\mathrm{S}$, the relatively high percentage carbohydrate (CHO) content in them (Fieldes, Deal and Tyson, 1977) must be taken into consideration. Isozymes 1 and 2 have similar molecular weights (loc. cit.), but the percentage $\mathrm{CHO}$ in isozyme 1 was significantly higher than that of isozyme 2 in both genotrophs; estimates of the order of 24 per cent and 14 per cent respectively were obtained. These figures, agreeing in magnitude with those of Shannon, Kay and Lew (1966) from horseradish peroxidases, emphasise the large fraction of the peroxidase molecule which must be affected by (a) genes coding for enzymes involved in CHO synthesis, and, (b) genes coding for enzymes involved in the assembly of the effective peroxidase molecule. Inclusion of the polypeptide portion suggests that at least three systems of structural genes have roles in producing peroxidase. 
The $R_{m}$ changes displaying segregation here were sharply demarcated. The size of the $R_{m}$ differences between corresponding isozymes from $\mathrm{L}$ and $\mathrm{S}$, as in the data here, contrasts with the smaller $R_{m}$ shifts superimposed by subsequent inducing treatments in the $\mathrm{C}_{1}$ and $\mathrm{C}_{2}$ generations on the

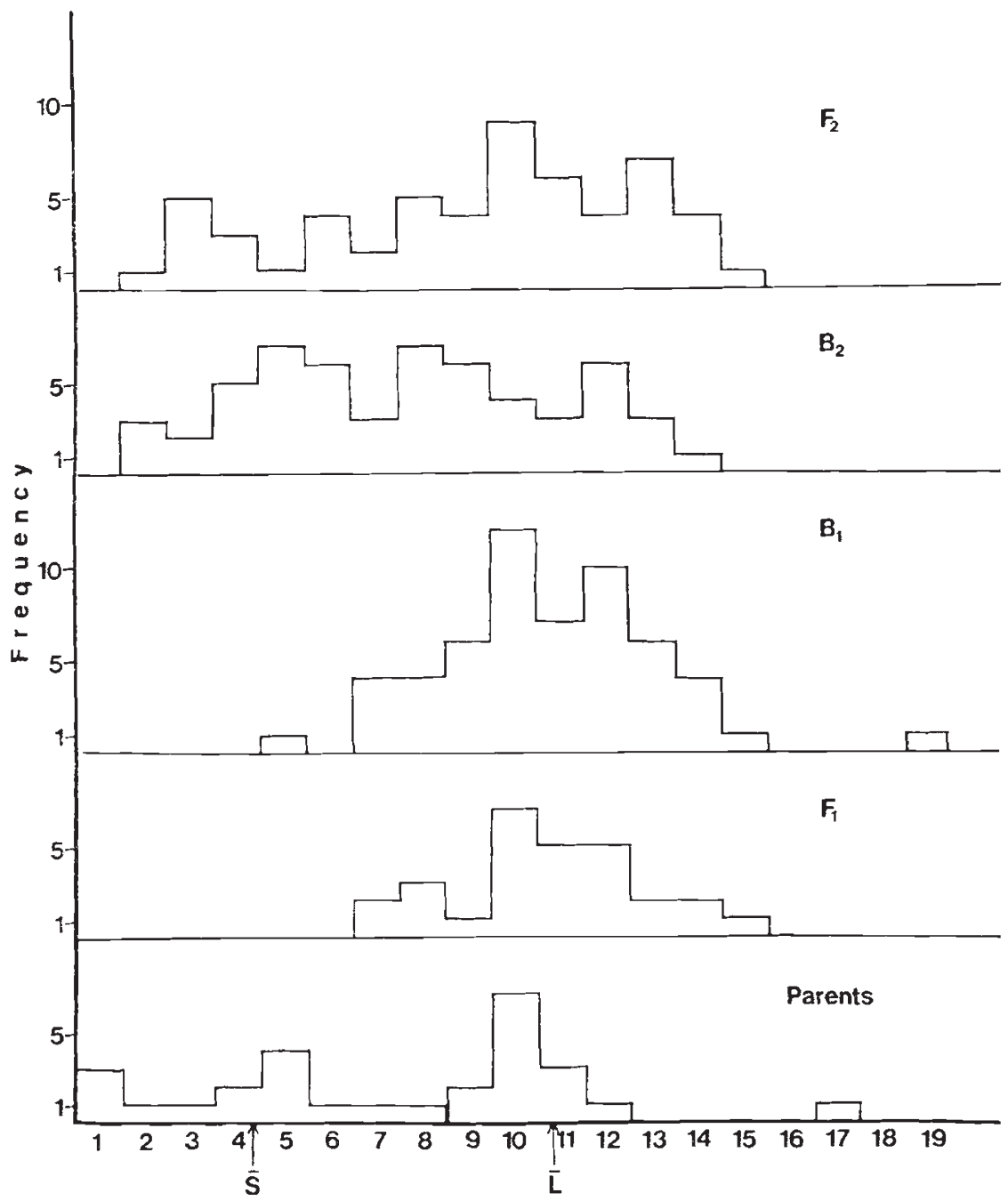

Frg. 1,--Isozyme 1 adjusted $R_{m}$ for each generation. $\mathrm{L}$ and $\mathrm{S}$ positions indicated by arrows on $x$ axis.

original $\mathrm{L}$ and $\mathrm{S}$ differences of the $\mathrm{C}_{\mathbf{0}}$ (Fieldes and Tyson, 1972), and with the yet smaller $R_{m}$ shifts detectable between isozymes from the stem base and apex (Fieldes, Tyson and Bashour, 1976). The range of $R_{m}$ differences represented in these three cases may reflect a range of degree of modification in the peroxidase molecule. In the context of very small $R_{m}$ changes, 
it is known that micro-heterogeneity (micro-banding) revealed through gel electrophoresis of apparently pure glycoprotein samples can originate in the variation possibilities of the CHO moiety (Gibbons, 1972).

The extent to which the CHO moiety of this glycoprotein may be

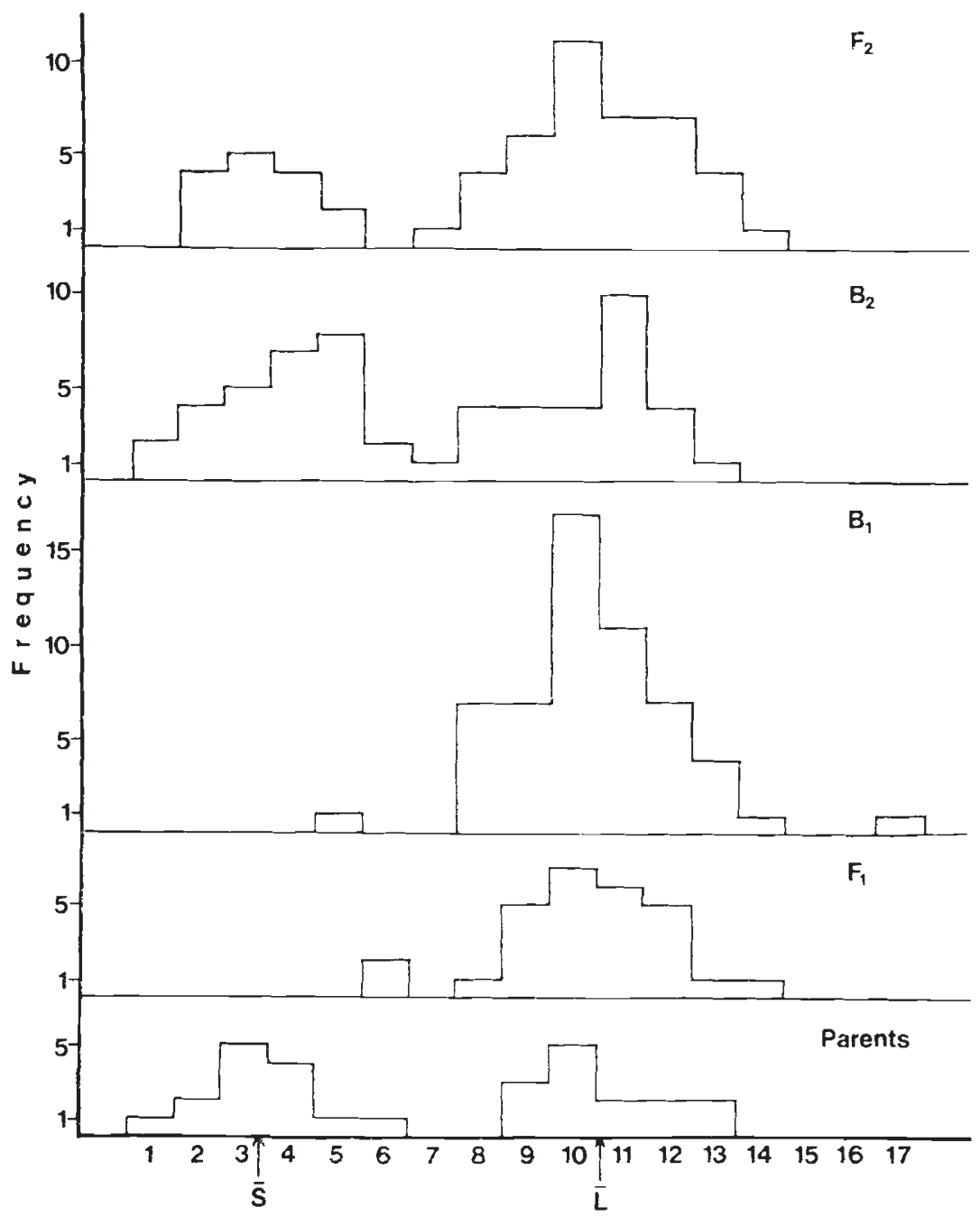

Fug. 2.-Isozyme 2 adjusted $R_{m}$ data for each generation. $\mathrm{L}$ and $\mathrm{S}$ positions indicated by arrows on $x$ axis.

responsible for the $R_{m}$ differences between corresponding $\mathrm{L}$ and $\mathrm{S}$ isozymes must obviously be examined along with the search for any polypeptide differences between corresponding isozymes. The likely connection of the peroxidase isozymes in the genotrophs to a physiological role in controlling IAA level, through their dual catalytic functions, gives further impetus to the detailed dissection of the $\mathrm{L}$ and $\mathrm{S}$ peroxidase isozymes. Peptide mapping 
techniques for peroxidase (Welinder, 1976) should help to clarify the differences underlying the $R_{m}$ shifts, and provide clues as to the origin and mechanism of the genotroph changes.

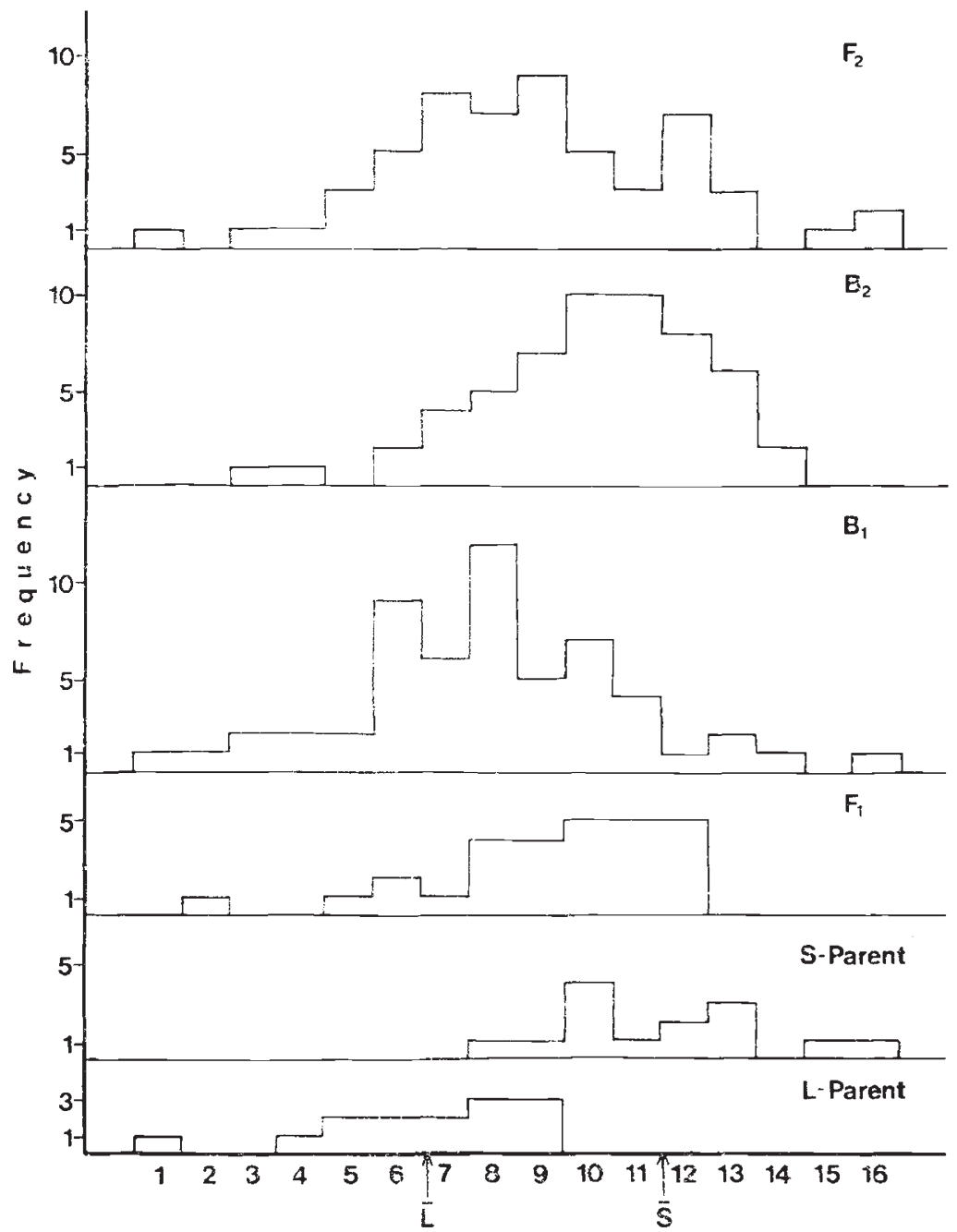

Fig. 3.-Peroxidase activity adjusted data for each generation. L and S positions indicated by arrows on $x$ axis.

Acknowledgements.-Thanks are extended to the National Research Council of Canada, whose financial assistance made this work possible, and to Dr Alan Durant, Aberystwyth, U.K., who very kindly provided seed of the $\mathrm{L}$ and $\mathrm{S}$ genotrophs which were used in the crosses.

\section{REFERENCES}

DURRANT, A. 1971. Induction and growth of Flax genotrophs. Heredity, 27, 277-298. FIELDES, M. A., AND TYSON, H. 1972. Activity and relative mobility of peroxidase isoenzymes $40 / 2-\mathrm{H}$ 
in genotrophs and genotypes of flax (Linum usitatissimum L.). Can. 7. Genet. Cytol., 14, 625-636.

FIELDES, M. A., AND TYSON, H. 1973a. Activity and relative mobility of peroxidase and esterase isozymes of flax (Linum usitatissimum) genotrophs. I. Developing main stems. Can. F. Genet. Cytol., 15, 731-744.

FIELDES, M. A., AND TYSON, H. 1973b. Activity and relative mobility of peroxidase and esterase isozymes of flax (Linum usitatissimum) genotrophs. II. $F_{1}$ hybrids and nuclear DNA reversion types. Can. F. Genet. Cytol., 15, 745-755.

FIELDES, M. A., DEAL, C. L., AND TYSON, H. 1977. Preliminary characterization of peroxidase isozymes isolated from two flax genotrophs. Can. 7. Bot., 55, 1465-1473.

FIELDES, M. A., TYSON, H., AND BASHOUR, N. 1976. Relative shifts in mobility in anionic peroxidase isoenzymes between stem base and apex of flax genotrophs. Phytochemistry, $15,247-250$.

Gibbons, R. A. 1972. Physico-chemical methods for the determination of the purity, molecular size and shape of glycoproteins. In Glycoproteins, Vol. 5, ed. A. Gottschalk, pp. 31-140. Elsevier Publishing Co., New York.

HART, M. A., TYSON, H., AND BLOOMBERG, R. 1971. Measurement of activity of peroxidase isoenzymes in flax (Linum usitatissimum). Can. F. Bot., 49, 2129-2137.

MURASHIGE, T., AND SKOOG, F. 1962. A revised medium for rapid growth and bio-assays with tobacco tissue cultures. Physiol. Plant., 15, 473-497.

Shannon, E. M., KAY, E., AND LEW, J. Y. 1966. Peroxidase isozymes from horseradish roots: I. Isolation and physical properties. 7. Biol. Chem., 241, 2166-2172.

WELINDER, K. G. 1976. Covalent structure of the glycoprotein horseradish peroxidase (EC 1.11.1.7). FEBS Letters, 72, 19-23. 